\title{
O $\mathrm{BONE} \& / \mathrm{O} / q_{\lambda}$ EXTENSILE POSTERIOR APPROACH TO THE ANKLE
}

\author{
A. G. HAYES, J. B. NADKARNI \\ From the District General Hospital, Southport, England
}

Surgical exposure of the ankle is usually obtained by an anterior approach, especially for replacement arthroplasty. The transfibular approach has been popular for arthrodesis.

We describe a new posterior approach to the ankle and posterior subtalar joint based on an extra-articular vertical calcaneal osteotomy behind the subtalar joint. The posterior flap so formed is hinged medially and offers wide exposure of the back of the ankle and posterior subtalar joint. This hinge allows safe and stable reduction of the osteotomised calcaneum, and the plane of dissection follows an 'internervous plane' behind the fibula.

We have had good results after using this incision in 12 patients with osteoarthritis or rheumatoid arthritis and there have been no difficulties with wound healing.

J Bone Joint Surg [Br] 1996;78-B:468-70.

Received 15 September 1995; Accepted 29 November 1995

The complex nature of the bones, ligaments and tendons which constrain the ankle does not allow easy exposure of the joint for joint replacement or full debridement before arthrodesis. Elevation of the fibula by a lateral approach provides an adequate exposure for arthrodesis (Crenshaw 1987), but is unlikely to give the stability necessary for prosthetic replacement. This is usually performed through an anterior approach with some difficulties of exposure and wound healing. A posterior approach with Z-plasty of tendo Achillis may lead to delayed wound healing and scarring and require a long period of immobilisation (Colton and Hall 1991).

A. G. Hayes, MCh Orth, FRCS, Consultant Orthopaedic Surgeon

J. B. Nadkarni, MCh Orth, Associate Specialist in Orthopaedics

District General Hospital, Town Lane, Kew, Southport, Merseyside PR8 6PN, UK.

Correspondence should be sent to Mr A. G. Hayes.

(C)1996 British Editorial Society of Bone and Joint Surgery 0301-620X/96/31175\$2.00

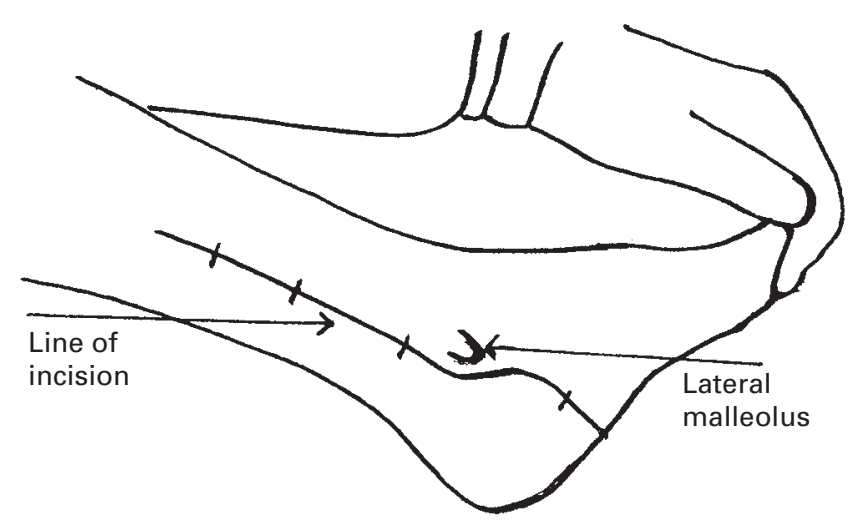

Fig. 1

Line of skin incision.

There is a plane behind the lateral malleolus which allows exposure of the back of the ankle and the posterior subtalar joint and avoids important vascular and neurological structures, but access is restricted (Hoppenfeld and De Boer 1994). If, however, the incision is extended into the sole of the foot, a vertical osteotomy of the calcaneus will allow the tissues behind and below the subtalar joint to be hinged medially. This exposes the back of the ankle and subtalar joints, making them readily accessible. The medial hinge prevents proximal migration of the osteotomy when it is closed at the end of the operation.

\section{PATIENTS AND METHODS}

We have used this approach in 12 patients. Table I gives the details. There were nine men and three women of mean age 62.5 years (42 to 76 ). Five had rheumatoid arthritis and seven osteoarthritis.

Operative technique. The patient is placed prone and the foot held free of the table by suitable padding. A pneumatic tourniquet is optional but is useful in the initial steps of the exposure.

An incision is made starting in the lower calf behind the fibula and extending distally around the back of the lateral malleolus. It then curves slightly anteriorly and then verti- 


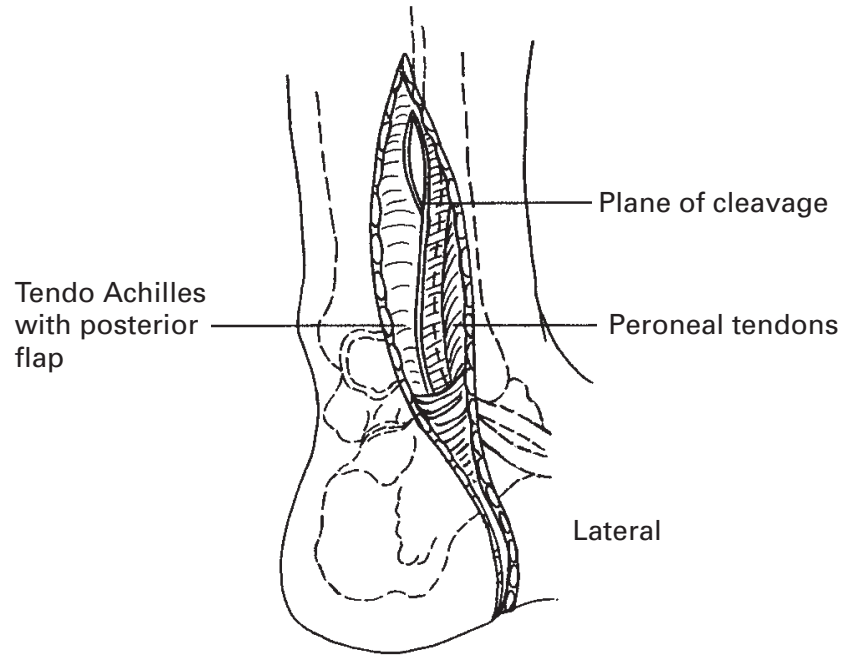

Fig. 2

Plane of superficial dissection on the lateral side of leg and foot.

Table I. Details of 12 patients who had an extensile posterior approach for ankle arthroplasty (A) or arthrodesis using external fixation (B) or internal fixation $(\mathrm{C})$

\begin{tabular}{cllll}
\hline Case & Age $(\mathbf{y r})$ & Sex & Diagnosis* & Operation \\
\hline 1 & 76 & $\mathrm{~F}$ & $\mathrm{RA}$ & $\mathrm{A}$ \\
2 & 42 & $\mathrm{~F}$ & $\mathrm{RA}$ & $\mathrm{A}$ \\
3 & 73 & $\mathrm{~F}$ & $\mathrm{RA}$ & $\mathrm{A}$ \\
4 & 76 & $\mathrm{~F}$ & $\mathrm{RA}$ & $\mathrm{A}$ \\
5 & 42 & $\mathrm{~F}$ & $\mathrm{RA}$ & $\mathrm{A}$ \\
6 & 73 & $\mathrm{~F}$ & OA & $\mathrm{B}$ \\
7 & 74 & $\mathrm{~F}$ & OA & $\mathrm{B}$ \\
8 & 67 & $\mathrm{~F}$ & OA & $\mathrm{B}$ \\
9 & 50 & $\mathrm{M}$ & OA & $\mathrm{B}$ \\
10 & 73 & $\mathrm{~F}$ & OA & $\mathrm{B}$ \\
11 & 54 & $\mathrm{M}$ & OA & $\mathrm{C}$ \\
12 & 50 & $\mathrm{M}$ & OA & $\mathrm{C}$ \\
\hline
\end{tabular}

$* \mathrm{RA}=$ rheumatoid arthritis; $\mathrm{OA}=$ osteoarthritis

cally down the lateral aspect of the heel into the sole of the foot anterior to the heel pad (Fig. 1). A tissue plane is developed above the calcaneus. In the sole of the foot the lateral soft tissues, including some of the plantar fascia, are separated from the underlying calcaneus. In the upper part of the incision the sural nerve is identified and its branches are retracted posteriorly together with the short saphenous vein, the superficial tributaries of which are cauterised.

The depths of the wound are developed to expose the superior and lateral surfaces of the calcaneus (Fig. 2). A vertical osteotomy of this bone immediately behind the most posterior part of the subtalar joint is opened up and hinged medially (Fig. 3). The structures on the back of the lower tibia and fibula, particularly the flexor hallucis muscle, are

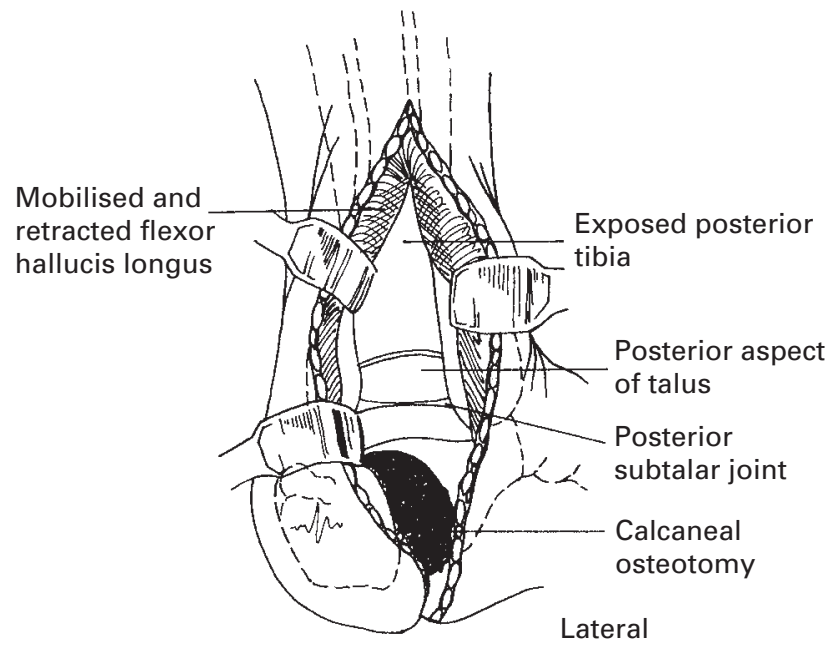

Fig. 3

Osteotomy of os calcis posterior to the subtalar joint.

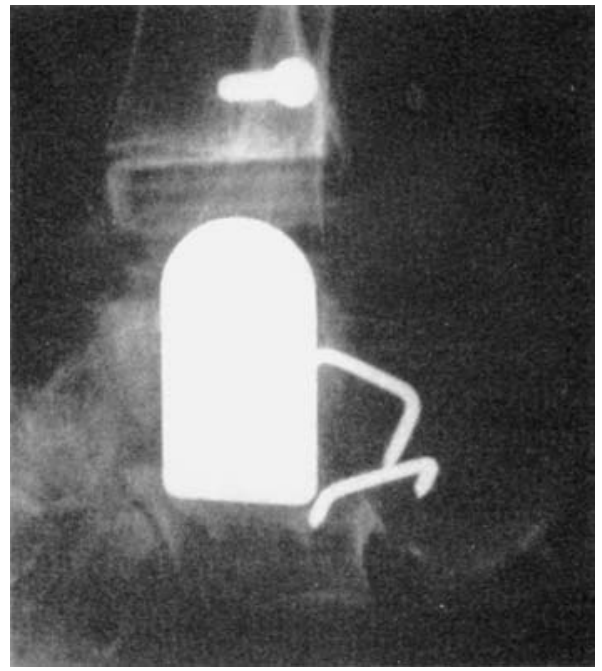

Fig. 4

Lateral radiograph of ankle seven weeks after replacement arthroplasty. The osteotomy of the calcaneum has united.

mobilised and retracted medially. The peroneal tendons and muscles are retracted laterally. This exposes the whole of the back of the ankle and the posterior subtalar joint. The articular surfaces are fully visible when the joint capsule is excised.

At the end of the operation the hinged flap which includes the posterior part of the calcaneus with the attached tendo Achillis and plantar tissues is restored to its normal position and held by sutures or staples. The wound is then closed over a suction drain by suture of the subcutaneous tissues and skin only. 


\section{DISCUSSION}

The approach is useful for both ankle arthroplasty and ankle arthrodesis. The posterolateral incision utilises the 'internervous plane' between the areas supplied by the peroneal and sural nerves. The osteotomy of the os calcis allows full exposure of the ankle and subtalar joints and the intact medial hinge ensures easy and stable reposition of the flap. The osteotomy of the calcaneum is through cancellous bone and heals in three to four weeks (Fig. 4). We have not seen any significant vertical migration of the posterior fragment. The skin incision on the sole of the foot lies anterior to the weight-bearing part of the heel pad and the scar has not given any problems. We have encountered no difficulties with wound healing, even in patients with rheumatoid arthritis.

No benefits in any form have been received or will be received from a commercial party related directly or indirectly to the subject of this article.

\section{References}

Colton CL, Hall AJ, eds. Atlas of orthopaedic surgical approaches. Oxford: Butterworth Heinemann Ltd, 1991:79-85.

Crenshaw AH, ed. Campbell's operative orthopaedics. 7th edition, Vol. 1. St Louis: CV Mosby Company, 1987:29-33.

Hoppenfeld S, De Boer P. Surgical exposures in orthopaedics. 2nd edition. Philadelphia, etc: JB Lippincott Company, 1994:530-9. 